\title{
FRAGMENTAÇÃO FLORESTAL E MUDANÇAS NA DISTRIBUIÇÃO BIOGEOGRÁFICA NA MICROBACIA DO RIO MÃO CURTA, SANANDUVA, RS.
}

\author{
Cleiva Perondii ${ }^{1}$, Kátia Kellem da Rosa ${ }^{2}$, Pedro Germano dos Santos Murara ${ }^{3}$.
}

1Graduada em Geografia, Universidade Federal da Fronteira Sul (UFFS), Erechim-RS, e-mail: cleivaperondi@gmail.com; 2 Professora no Departamento de Geografia - Instituto de Geociências, Universidade Federal do Rio Grande do Sul, Porto Alegre-RS, e-

mail:katia.rosa@ufrgs.br; Professor da Universidade Federal da Fronteira Sul, Erechim- RS e-mail: pmurara@gmail.com

Recebido em 05/2016. Aceito para publicação em 06/2016.

Versão online publicada em 06/2018 (http://seer.ufrgs.br/paraonde)

\begin{abstract}
Resumo: $\mathrm{O}$ artigo objetiva investigar as causas do desaparecimento de espécies pertencentes à macrofauna na microbacia do Rio Mão Curta, no município de Sananduva-RS. Foram analisados dados em campo e de sensores remotos integrados em um SIG para a realização de mapeamento da área e forma dos fragmentos e corredores ecológicos. Realizou-se entrevistas com moradores e aplicação de técnicas biogeográficas em atividade de campo. As teorias e métodos biogeográficos e da Ecologia da paisagem basearam a análise dos fatores relacionados com possíveis perdas das características do habitat, assim como diminuição populacional das espécies investigadas e avaliar o status atual da biodiversidade. Os dados obtidos em campo e as entrevistas na microbacia evidenciaram que alterações no uso e ocupação do solo com o tempo representam importantes fatores distributivos relativos ao habitat. As principais espécies da macrofauna sofrem as consequências da destruição de seu habitat, redução de alimentos entre outras influências. Com o mapeamento foi possível analisar alto grau de fragmentação das áreas de mata e pouca conectividade entre os fragmentos e drenagem, o que representa indicativos de escassez de recursos naturais e condições limitantes para o desenvolvimento de algumas espécies. A pesquisa revela que fatores como desmatamento, ocupação agrícola, diminuição de acesso à drenagem, prática da caça e o uso de agrotóxicos influenciam na distribuição biogeográfica de espécies que pertencem a macrofauna na área de estudo. Os resultados contribuem para o planejamento de ações de conservação e monitoramento ambiental na área de estudo.
\end{abstract}

Palavras-chave: Macrofauna; Conectividade; Ecologia da paisagem;

Abstract: This paper aims to investigate the causes of the disappearance of large animals species in the watershed Mão Curta River, in the municipality of Sananduva-RS. Field activities and remote sensing data integrated into a GIS to perform thematic mapping of the area to identify the shape of ecological fragments and corridors. Interviews were conducted with residents beyond the application of biogeographical techniques in the field of activity. Theories and methods biogeographics and Landscape Ecology were basis for analysis of the factors that are related to possible losses of habitat features, as well as population decrease of the investigated species and to assess the current status of biodiversity. The results showed that the changes in the use and land cover over time are important distributional factors. The main species of animals large suffer the consequences to destruction of their habitat and reduction of food. The fragments and corridors mapping analysis showed that there is a high degree of fragmentation of forest areas and the poor connectivity between fragments and those with drainage, which is indicative of scarcity of natural resources and limiting conditions for development some species. From this research it was possible to understand that factors such as deforestation, agricultural occupation, decreased access to drainage, hunting practices and the use of pesticides influence the biogeographical distribution of species belonging to animals large in the study area. The results contribute to the planning of conservation actions and environmental monitoring in the study area.

Keywords: Large Animals; Connectivity; Landscape Ecology. 


\section{INTRODUÇÃo}

O Brasil é considerado um dos países mais rico em biodiversidade (MMA, 2002), detentor de uma megabiodiversidade biológica, estima-se que no Brasil esteja em torno de $20 \%$ de toda a biodiversidade existente no planeta. Destaca-se que estudos relacionados à grande biodiversidade nacional, ainda são pouco satisfatórios, pois verifica-se recorrentes casos de problemas ligados à redução do número de espécies (MORATO \& CAMPOS, 2000; VIADANA

2004).

Estudos referentes à perda e fragmentação de habitat ou unidades da paisagem, também pela abordagem da Ecologia da Paisagem, tem elevada importância, pois de acordo com Lago et al. (2001, p.1634) "a área do fragmento é, em geral, o parâmetro mais importante para explicar as variações de riqueza de espécies".

A identificação de fragmentos florestais torna-se uma importante ferramenta (ou técnica) para análise da redução do número de espécies animais. Entendido como uma área de vegetação natural que foi interrompida pela ação natural ou antrópica (barreira), um fragmento florestal proporciona (ou resulta) na diminuição do número, e do fluxo de espécies. Portanto, o efeito borda é importante na análise do isolamento e do tamanho do fragmento florestal resultante da ação da barreira (antrópica ou natural), no sentido de medir as alterações dos processos que ocorrem naquele ecossistema, uma vez que as modificações resultantes da formação dos fragmentos e do isolamento das espécies causam profundas alterações na dinâmica das populações de animais e vegetais.

De acordo com o Ministério do Meio Ambiente (SCD, 2010), as causas que mais interferem na extinção, degradação e fragmentação de ambientes naturais são os resultantes da abertura de grandes áreas para implantação de pastagens ou agricultura convencional, e ainda, a poluição e as ocupações irregulares.

Forman (1985, apud LAGO 2001) explica que a riqueza da biodiversidade diminui paralelamente ao tamanho do fragmento devido à área que a mesma necessita para a sua sobrevivência, que varia de acordo com a espécie. A área mínima que cada espécie necessita para sua manutenção é determinada pelo tamanho do território e pela quantidade da população, o aumento ou diminuição da área de um fragmento provoca a redução dos recursos naturais necessários para a sobrevivência o que pode acarretar as competições entre as diferentes espécies ou mesmo entre 
indivíduos de uma mesma espécie. E este contato denominado intra ou interespecífico tem sua parcela de contribuição para o equilíbrio do ecossistema juntamente com os fatores bióticos e abióticos. Estes são denominados por Ricklefs (1996) como fatores limitantes ou recursos os quais são responsáveis diretos pela regulação da população, pelo seu declínio ou seu sucesso. Esse tipo de controle externo faz com que o tamanho efetivo da população seja diretamente proporcional à quantia de recursos naturais disponíveis que, por sua vez, é diretamente proporcional ao tamanho do habitat (METZGER, 1998).

A fragmentação do habitat traz consequências diretas para as espécies, já que os desconecta e isso impede a mobilidade e interação. As espécies da área fragmentada podem sofrer com o efeito de borda já que este regula a temperatura, umidade entre outros elementos importantes para a sobrevivência. Estes estão relacionados com o tamanho do habitat e sua forma (COLLINGE, 1996).

Com relação às espécies de mamíferos, o efeito de borda causa algumas consequências negativas. De acordo com estudos realizados em fragmentos de Mata Atlântica no estado de Sergipe constatou-se que há diferenças no ambiente em relação à temperatura e umidade do ar e do solo em uma faixa de 60 metros em direção ao interior do fragmento e o número de indivíduos e a diversidade de pequenos mamíferos observados em uma faixa de até 160 metros a partir da borda apresentam diferenças significativas em relação ao observado no interior dos fragmentos (STEVENS e HUSTBAND, 1998).

A fragmentação das manchas pode ser dar por vários motivos, em áreas com ocupação humana, por exemplo, a paisagem pode se tornar um mosaico fragmentado. E a matriz pode ser impactada pela atividade humana, seja ela marcada pela pecuária, agricultura ou até mesmo pela urbanização. E em menores proporções manchas que funcionam como habitat naturais para a biota regional. As dimensões das manchas, suas formas e a disposição espacial de seu conjunto determinam as suas qualidades como habitat para a biota local (COLLINGE, 1996).

Dessa forma a vegetação apresenta-se em diversos níveis de sucessão de modo gradual, a resolução do Conselho Nacional do Meio Ambiente (CONAMA) no 417, de 23 de novembro de 2009 classifica os estágios da vegetação em áreas de Mata Atlântica, considera em seu primeiro artigo que a vegetação primária se trata daquela que apresenta nível elevado de biodiversidade e com 
mínimos efeitos causados pelo ser humano com o intuito de não causar impactos e mudanças na diversidade de espécies e estruturas originais, em seu segundo artigo especifica a vegetação secundária a qual de acordo com o artigo segundo se trata de vegetação herbácea, arbustiva ou arbórea, que se regeneraram de forma natural, após cerceamento pela ação humana.

Objetivando contribuir no estudo e técnicas de análise da redução da biodiversidade, tomou-se como área de estudo a microbacia do Rio Mão Curta, localizada no município de Sananduva, na região do planalto médio, ao nordeste do estado do Rio Grande do Sul. A área de estudo integra o bioma de Mata Atlântica, este por sua vez é rico em biodiversidade, abrigando inúmeras espécies endêmicas.

0 presente artigo objetiva investigar as possíveis mudanças na distribuição biogeográfica de espécies da macrofauna na microbacia do rio Mão Curta e relações com alterações no habitat, analisando as mudanças na dinâmica da paisagem relacionando com o aumento da fragmentação e efeito borda das áreas de cobertura vegetal nativa bem como a diminuição da conectividade da mesma. A partir disso inferir como caça e o uso de agrotóxicos podem contribuir para a diminuição de espécies e avaliar as possíveis alterações na manutenção dos recursos naturais indispensáveis para as referidas espécies da macrofauna.

\section{2 ÁREA DE ESTUDO}

A microbacia do Rio Mão Curta está localizada entre as coordenadas $27 \circ 50^{\prime} 50,5^{\prime \prime}$ S e $51^{\circ} 55^{`} 03^{\prime \prime} \mathrm{W}$ ao nordeste do estado do Rio Grande do Sul, na zona rural do município de Sananduva - RS (Figura 1) o qual possui aproximadamente 15.373 habitantes e área aproximada de $504,54 \mathrm{~km}^{2}$ tem sua economia baseada na agropecuária (IBGE, 2010).

A mesma situa-se em área de clima subtropical IVa classificado por Rossato (2011) o qual recebe menor influência de sistemas polares e maior atuação dos sistemas marítimos e tropicais continentais nas estações primavera e verão, quando associados, os dois sistemas citados anteriormente associados ao fator relevo contribuem para a elevação ou aumento dos níveis ou registros de precipitação.

0 rio Mão Curta possui curso de água intermitente. Em sua área há predominância de solo do tipo Latossolo roxo em áreas planas (ATLAS SOCIOECONÔMICO DO RS, 2013). Já em áreas com vertentes inclinadas há a ocorrência de neossolo litólico (STRECK et al, 2008). A microbacia do rio Mão 
Curta situada geologicamente na Bacia do Paraná Na região fisiográfica do Planalto Médio ao nordeste do estado do Rio Grande do Sul, onde se situa o município de Sananduva - RS e mais especificamente a microbacia do rio Mão Curta apresenta relevo com áreas suavemente onduladas.

Possui vegetação nativa característica do bioma de Mata Atlântica entremeado por florestas de araucária, classificado como floresta ombrófila mista, sendo que a espécie vegetal que se destaca é a Araucária angustifólia, a qual vem tendo sua área reduzida desde o período da colonização italiana sem que houvesse preocupação com sua conservação (SONEGO, BACKES \& SOUZA, 2007). Este problema afeta a biodiversidade, já que sua conservação não é realizada de maneira eficaz. Dentre as espécies ameaçadas de extinção podese citar a onça pintada (Panthera onca), o veado mão curta (Mazama nana) (ICMBio, 2014). Há também algumas espécies que comumente são encontradas em áreas características ao bioma da mata atlântica como a lebre (Lepus capensis), cutia (Dasyprocta azarae), paca (Agouti paca), capivara (Hydrochaeris hydrochaeris), anta (Tapirus terrestres), jaguatirica (Felis pardalis), puma (Felis concolor), coati (Nasua nasua), lobo guará (Chrysocyon brachyurus), tatu mulita (Dasypus hybridus e outros (SILVA, 1994). 
Figura 01 - Localização da área de estudo. Mosaico de imagens Digital Globe 2014.

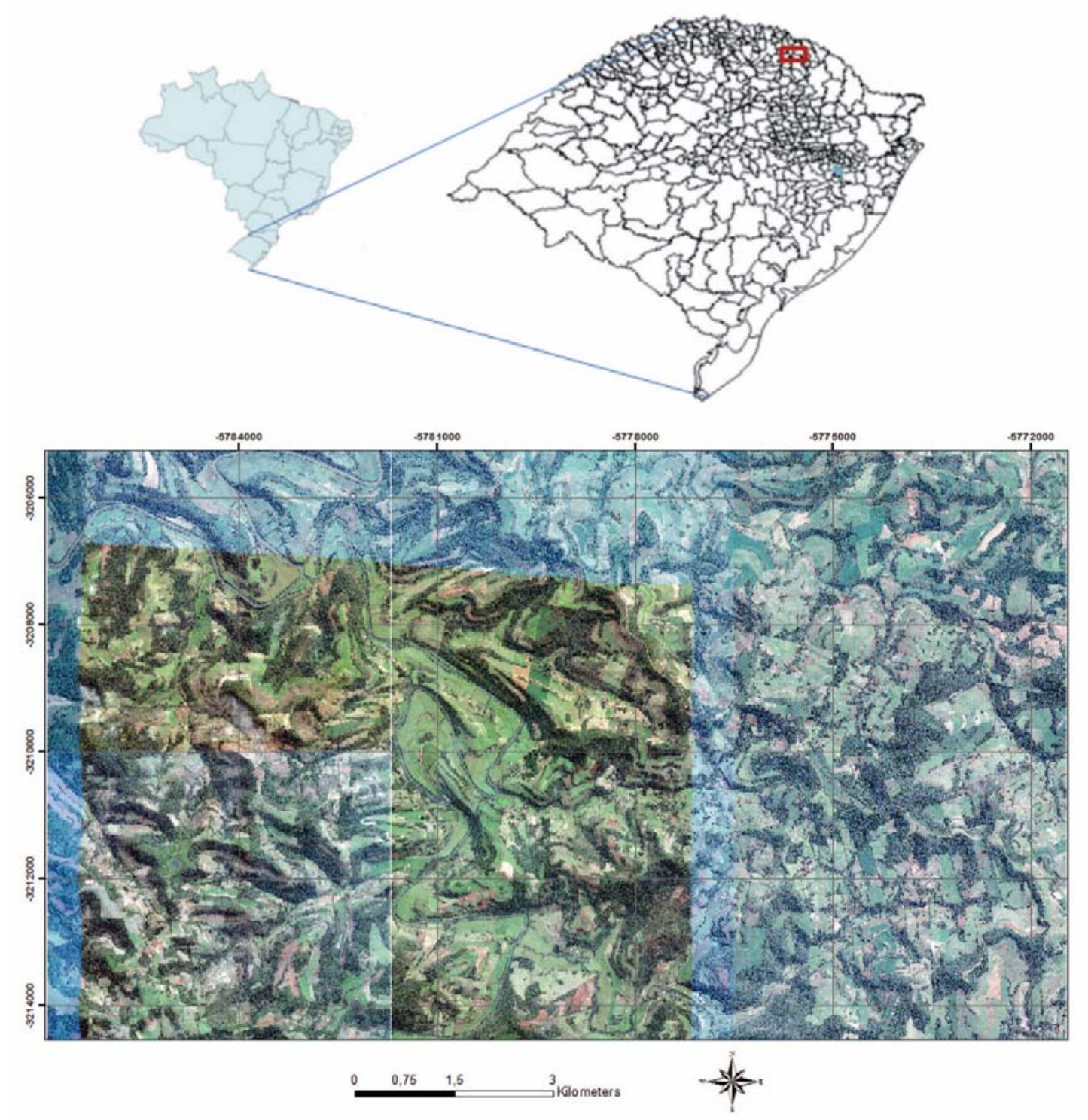

\section{MATERIAIS E MÉTODOS}

Para o desenvolvimento deste trabalho foram obtidos dados sobre mudanças na paisagem local nas ultimas três décadas em campo através de entrevistas e ainda observações com técnicas biogeográficas em campo na área da microbacia do rio Mão Curta.

$$
\text { As entrevistas desenvolvidas }
$$
foram baseadas no método pesquisa qualitativas por grupo focal, a qual baseia-se na reflexão e compreensão a partir das informações dos 
participantes sobre o tema préestabelecido pelo pesquisador (NETO et al., 2002).

Em campo foram observados os indicadores biogeográficos, como por exemplo, presença de recursos hídricos e sua qualidade, fonte de alimentos, características do habitat, grau de fragmentação e sua distribuição, área de borda, presença ou não de corredores e impactos que as atividades agrícolas adjacentes causam na biodiversidade, nível de fragmentação, vestígios de mamíferos, presença de serapilheira. A partir da observação em campo, optou-se pela utilização da técnica biogeográfica de busca por evidências da presença de macrofauna, tais como ninhos, tocas e outros tipos de abrigo, resíduos de alimentos, ruídos, tipos de vegetação frutífera que vem crescendo recentemente, pegadas, pelos, entre outros vestígios de sua existência em determinado local.

A escolha dos fragmentos a serem analisados em campo, nas imagens no Google Earth foram realizados com o intuito de planejar um roteiro de trabalho de campo para coleta de dados.

Com a utilização de imagens de satélite, obtidas em 2014, do Google Earth (DIGITAL GLOBE) com coordenadas UTM e sistema datum WGS84 com alta resolução espacial (4 m), baseado nos dados de campo, foram mapeados os fragmentos de vegetação e os corredores. 0 mapeamento foi gerado e integrado em um Sistema de Informações Geográficas (SIG) no software Quantum Gis - QGIS (livre e disponível para utilização na internet disponível para download no seguinte endereço http://www.qgis.org/en/site/forusers/ download.html) e no ARCGIS. A partir do mapeamento de alta resolução gerado analisou-se o grau de fragmentação, forma e tamanhos relativos dos fragmentos, o efeito borda, a qualidade dos fragmentos e verificado o grau de conectividade entre os fragmentos através de corredores.

Os programas QGIS e ARCGIS foram utilizados para a realização do mapeamento dos fragmentos, categorizados em vegetação primária e 
Vegetação secundária, esta classificação foi feita com base na resolução do CONAMA 417 de 23 de novembro de 2009, porém as áreas de vegetação secundária foram divididas em vegetação secundária em avançado estágio de regeneração, vegetação secundária em baixo estágio de regeneração, devido às características do tamanho e densidade das mesmas. Além destas classes mapearam-se áreas de reflorestamento, corredores e drenagem.

\section{RESULTADOS E DISCUSSÕES}

a) Análises das observações de campo e entrevistas

A atividade de campo foi dividida em duas etapas sendo a primeira voltada a observação e análise do curso do rio Mão Curta, foi percorrido todo o percurso do mesmo, já na segunda parte o foco do trabalho de campo foi na aplicação de técnicas biogeográficas em áreas demarcadas a priori. A partir deste foi possível observar que o Rio Mão Curta, nasce na parte mais alta da área da microbacia em uma altitude de aproximadamente 647 metros na qual há presença de impactos causados pelo homem, esta área possui vegetação nativa, porém cerca de três metros a jusante foi aberta uma estrada para ter acesso a lavouras dessa forma acaba impactando tanto a nascente do rio como o fragmento da mata e sua biodiversidade (Figura 2a).

Em seu alto curso (Figura 2b), o rio Mão Curta apresenta em seu leito normal estreito em torno de 1,5 metros, pouca quantidade de água, mas com fluxo turbulento corrente, já no médio curso (Figura 2c) seu fluxo apresenta em maior proporção características de um rio com fluxo turbulento corrente, podendo-se observar que em suas margens há presença de depósitos de colúvio e aluvionares e em algumas poucas áreas percebe-se que se torna laminar, além da presença de poluentes como restos de plásticos e roupas (Figura 2d). No baixo curso (Figura 2e), região mais próxima a sua foz, a característica predominante de seu canal é de fluxo laminar. Outro problema observado no baixo curso deste rio são áreas de seu curso que não possuem vegetação ciliar, pois estes trechos são utilizados 
para que os animais, bovinos Mão Curta tem sua foz em estuário no principalmente, tenham acesso para Rio Apuaê. sua dessedentação. Neste ponto o rio

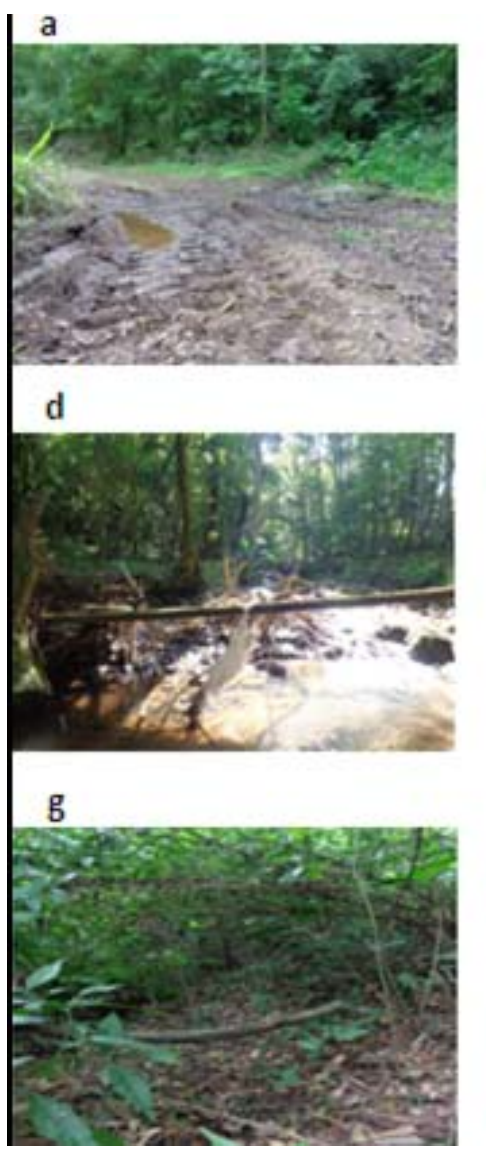

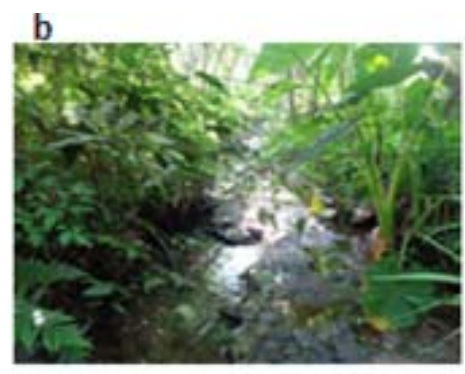

e

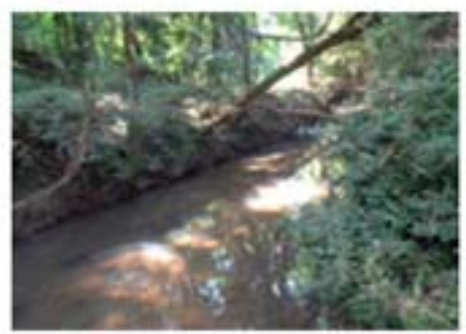

h

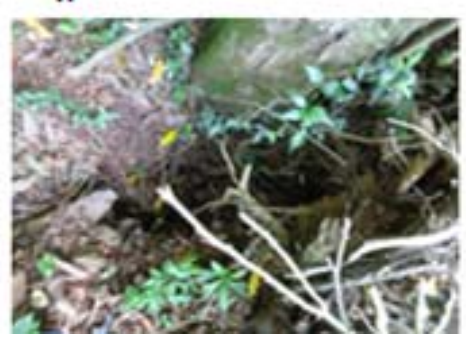

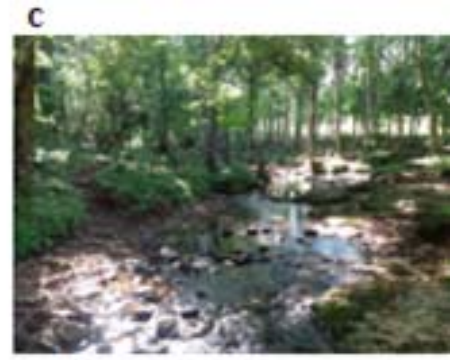

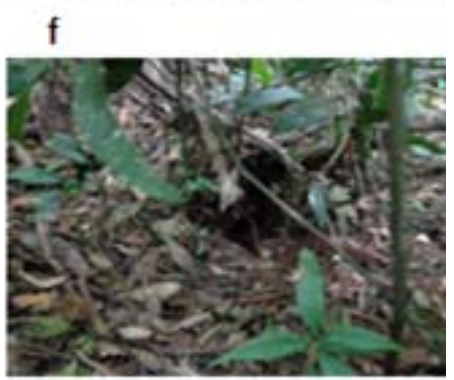

i

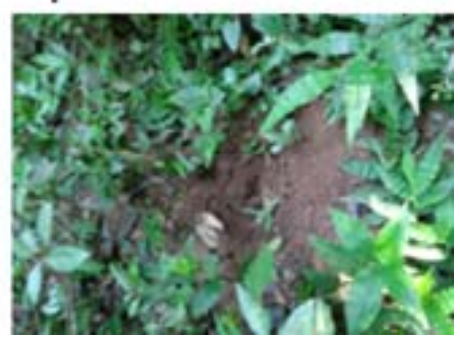

Figura 2- (a) Área de Nascente do rio Mão Curta impactada pela abertura de estrada e tráfego de máquinas agrícolas. (b) Alto curso do rio Mão Curta. (c) Médio curso do rio Mão Curta. (d) Lixo encontrado no médio curso do rio Mão Curta. (e) Baixo curso do rio Mão Curta. (f)- Ao centro da foto, toca de um tatu. (g) - trilha, (h) - toca. (i) - Pegadas de capivara (Hydrochaeris hydrochaeris).

Na segunda etapa do trabalho de campo foram visitados cinco fragmentos que haviam sido demarcados e localizados no Google Earth, e em cada um deles foi observado diversos elementos como localização, exposição solar, inclinação do terreno, posição topográfica, solo, umidade do solo, erosão, proximidade da drenagem, tipo de vegetação, bem como sua densidade e estágio sucessional da vegetação. Além dos elementos citados, durante as atividades de campo foram aplicadas algumas técnicas de estudos biogeográficos as quais servem para obter dados sobre os seres vivos e a interação que os mesmos têm com o ambiente em que estão inseridos, e estas informações podem ser subsídios para o entendimento 
da distribuição geográfica durante determinado espaço de tempo e também no espaço (ROCHA, 2011). As seguintes técnicas biogeográficas foram utilizadas nos fragmentos selecionados: observação e registro de sons, observação e registro de pegadas e trilhas de animais, visualização e registro de resíduos ou restos de animais, de locais de repouso, refúgio, pouso, ninhos, tocas e abrigos de animais.

No primeiro fragmento visitado se trata da área de nascente do rio Mão Curta a mesma apresenta terreno ondulado, sua borda possui alta exposição solar, solo coberto pela serapilheira, a umidade do mesmo diminui do interior para a borda, pouco erodido, em seu interior encontramse espécies de mata nativa como o pinheiro do Paraná. Possui corredor, porém o mesmo apresenta sua vegetação bastante agredida e rarefeita em função das atividades agrícolas que ocorrem na proximidade. Neste fragmento de mata verifica-se que o mesmo possui uma série de problemas como presença de estrada para dar acesso à lavoura que há no lado oposto, na qual nota-se que existe fluxo de veículos pesados como tratores $\mathrm{e}$ caminhões.

Outro aspecto a se destacar se trata das áreas de lavoura de trigo que fazem divisa com o fragmento e que ao ser colhido foi substituído pela soja, a partir disso pressupõe-se uma série de outros problemas que existem ali como o uso intensivo de agrotóxicos que com a proximidade da nascente do rio Mão Curta a probabilidade de contaminação torna-se grande, ruído de máquinas que pode afugentar os animais, dentre outros. Constata-se que se encontra mal conservado.

Neste fragmento a vegetação encontra-se em estágio avançado de regeneração, a densidade da mesma varia da borda para o interior, sendo que na borda a vegetação é mais rarefeita se comparada com o seu interior, há mudanças também na temperatura e umidade. No que diz respeito à temperatura foi possível identificar com auxilio de um higrômetro uma diminuição, sendo que na área de borda ao mensurar a mesma encontrava-se em $29,9 \circ \mathrm{C}$ e em direção ao interior do fragmento esta diminuiu para 28 드 , já a umidade do ar ao interior deste aumentava significativamente, na área de borda a mesma encontrava-se a $74 \%$ no interior a mesma aumentava para $76 \%$. Foi possível verificar uma mudança de 1,9 으 para menos da borda em direção ao interior. A umidade do ar, ao passo que adentrávamos a mata aumentou $2 \%$. Temperatura e umidade são elementos importantes que caracterizam o habitat de 
mamíferos, neste fragmento o vestígio (toca) encontrado foi na área de borda.

$\mathrm{O}$ que se verificou foram tocas na borda do fragmento, que segundo seus aspectos são características do tatu mulita (Dasypus septemcinctus) sendo que no momento das entrevistas esta espécie foi mencionada como vista ocasionalmente nas redondezas. O tatu mulita possui preferência por habitar bordas de matas, áreas de vegetação menos densa, costuma alimentar-se de insetos, raízes, minhocas e possui ótimo faro (EMBRAPA, 2013).

$\begin{array}{ccr}\text { O } & \text { segundo } & \text { fragmentado } \\ \text { vegetacional } & \text { analisado } & \text { apresenta }\end{array}$
características de vegetação secundária e isolado dos demais fragmentos. Esta área encontra-se isolada dos demais por não possuir corredor, no período do trabalho de campo a mesma encontrava-se cercada por lavouras de trigo, sua vegetação secundária encontra-se em nível baixo de regeneração com espécies herbáceas, arbustivas e arbóreas, seu solo bastante seco, há presença de uma camada incipiente de serapilheira que o recobre, relevo íngreme, sem mudança de temperatura. Não foram encontradas evidências da presença de mamíferos, por ser uma área isolada das demais sem Na quarta parada se trata de um reflorestamento feito de pinus americano, presença de recursos hídricos e de corredores ecológicos. Esta área encontrase bastante suscetível a problemas vinculados a agrotóxicos devido à lavoura próxima, a estrada que há em meio ao fragmento, inclusive há vestígios de que uma antiga fonte de água existia no local, mas que hoje está seca. O terceiro ponto foi visitado por ser um fragmentado de vegetação nativa de difícil acesso em seu interior o mesmo é um dos poucos que ainda restam na área de estudo, tanto que a mesma encontra-se melhor conservada somente em um dos lados da vertente e de outro sua vegetação já foi retirada em algumas áreas. A área deste fragmento é bastante inclinada, possui fonte de alimentos e recursos hídricos, seu solo apresenta cor escura e recoberta por serapilheira, possui vegetação desde o extrato herbáceo ate o arbóreo, vegetação bastante densa, dificultando o acesso humano ao seu interior. Em meio ao mesmo e nas proximidades foram encontrados alguns vestígios como trilha e tocas (Figura $2 \mathrm{~g}$ e $2 \mathrm{~h}$ ). Com o auxílio do higrômetro verificou-se que há grande mudança de temperatura e umidade entre a borda do fragmento e o seu interior sendo que neste dia houve mudança de $2,5 \circ \mathrm{C}$.

o qual é plantado com o propósito de retirar o mesmo para vender a madeireiras 
instaladas no município, mas no dia que as atividades de campo foram realizadas ao chegar ao local observamos que a vegetação havia sido toda retirada para posterior correção do solo e cultivo de soja.

A foz do rio Mão Curta foi o quinto ponto a ser realizado trabalho de campo, local com presença de vegetação arbustiva e arbórea, alguns trechos da drenagem da margem direita do rio são utilizados para a dessedentação de bovinos, há também estradas que cortam este fragmento, a vegetação da margem direita encontra-se fragmentada, o solo erodido por conta do pisoteio do gado e retirada de mata para a passagem dos bovinos. Nesta área foram encontradas pegadas de capivara (Hydrochaeris hydrochaeris) (figura 2 i), estas frequentam o local devido a presença de capim para se alimentar água para beber, nadar, e vivem também em áreas de terra firme onde pastam. Esses animais de acordo com moradores da microbacia são alvo de caçadores que as procuram devido a sua carne, para tanto utilizam armadilhas e até mesmo armas de fogo para captura-las e matá-las.

Ao trabalhar com as informações obtidas nas entrevistas percebe-se que sob o ponto de vista da população ocorreram várias modificações na paisagem onde vivem, como por exemplo, o uso do solo, aumento do uso de agrotóxicos, diminuição de pessoas no local, menor visibilidade de animais que pertencem a macrofauna, como o tatu, a jaguatirica e o veado. De acordo com o trecho da fala do entrevistado $B$ nota-se de forma nítida que houve mudanças "[...] o mato tão destruindo com os tratores para plantar soja e milho, o que se planta pra comer nasce, mas precisa de muitos cuidados, antigamente não precisava, hoje o pessoal usa muito veneno $[\ldots]$ " para o mesmo em torno de trinta anos passados o cultivo de soja era insignificante diante dos produtos alimentícios plantados pelas famílias.

Verifica-se com as narrativas que a aplicação de agrotóxicos aumentou significativamente em comparação há trinta anos pretéritos, e diminuíram as variedades agrícolas que se produzia na referida área de estudo,

[...] o pessoal tá plantando bem menos variedade, o que se tem aqui como fonte de renda é basicamente milho, soja e pecuária, trinta, quarenta anos havia aqui em média de 40 culturas, porque o pessoal plantava comida pra família e hoje as pessoas escolheram por trabalhar com poucas atividades, talvez nem mais pro sustento da família e dai se acaba comprando o alimento" (Entrevistado A)

O uso indiscriminado de agrotóxicos vem sendo ampliado por ser 
eficaz no combate a pragas agrícolas, porém não atinge somente seus alvos e sim este contamina outras espécies, o solo, água, o ar e o próprio ser humano.

Relativo ao solo este perderá parte de seus nutrientes, pois com a retirada de sua cobertura vegetal ocorrerão processos erosivos, a chamada erosão laminar, a qual consiste na perda da camada superficial do solo, sendo assim para que este terreno possa voltar a produzir irá necessitar de fertilizantes inorgânicos, os quais se utilizados demasiadamente podem afetar a qualidade biológica do vegetal e também contaminar corpos de água.

Este aspecto da poluição do lençol de água subterrâneo está presente na fala de um dos entrevistados, o mesmo aponta que com o uso exagerado de agrotóxicos para os cultivares de soja e milho principalmente "não dá nem mais pra confiar na água da fonte que sempre se usou, dai tem que cavar o poço mais fundo que der isso é um problema sério", ao atentar para o final desta fala nota-se que o entrevistado vê a perfuração de poços como um "problema sério" pelo custo que o mesmo tem e também pela capacidade de abastecimento que o mesmo precisa para atender a demanda de água necessária.

Outro elemento destacado na entrevista diz respeito ao desmatamento o qual contribui para mudanças visuais na paisagem, o entrevistado $A$ aponta que [...] hoje quando a gente olha pra paisagem aqui da comunidade, [...] tudo mudou em relação a trinta, quarenta anos atrás, deu uma boa diminuída nas plantas e como consequência também nos animais foram embora porque quase não se vê mais.

Percebe-se na fala de alguns entrevistados os mesmos correlacionam as modificações na paisagem pelo desmatamento com as mudanças biogeográficas "antigamente o mato vinha até perto das casas era bem mais fechado hoje quando tu olha a primeira coisa que você vai ver são lavouras e pouco mato talvez essa mudança da paisagem que teve tá ligada com a diminuição dos animais"(entrevistado F). Sabe-se que quanto maior o fragmento maior será a diversidade biológica desta área e viceversa, nesse sentido Metzger (1998) afirma que o a área do fragmento se trata do parâmetro mais importante capaz de determinar a riqueza das espécies.

E essas lavouras hoje se apresentam com características diferentes de acordo com a fala do entrevistado C, pois produzem poucas variedades, mas em quantidade elevada e aplicam níveis elevados de agrotóxicos o qual polui e mata os recursos que servem como alimento para outras espécies animais o 
que afugenta as mesmas que acabam procurando outros locais ou morreram como, por exemplo, o veado mão curta, o qual deu nome à comunidade e ao rio.

O desmatamento na microbacia estudada vem ocorrendo não só para dar espaço a agricultura, de acordo com o entrevistado $F$, mas também para ser queimada nas atividades diversas que as famílias que ali residem realizam no decorrer do ano especialmente no inverno período do ano que a lenha extraída da mata serve como matéria prima para o aquecimento de fogões domésticos, para cozinhar o açúcar mascavo produzido no local e até mesmo para a venda.

A presença de espécies exóticas e principalmente a retirada da vegetação nativa para dar espaço às mesmas causa grande impacto para a biodiversidade. Para Hirt (2004), a silvicultura vem se mostrando cada vez mais presente na paisagem causando mudanças significativas na mesma já que esta espécie tem um desenvolvimento mais rápido em relação à Araucária, gerando mudanças não só na vegetação e sim na fauna.

Outro problema de notável relevância para mudanças ligadas a biodiversidade na área de estudo se trata de caça ilegal, a qual é tida por muitos como lazer e raramente fiscaliza-se estas ações na área de estudo, durante a entrevista este tema foi abordado e caracterizado pelo grupo como um esporte desnecessário, pois “[...]ninguém daqui da comunidade precisa matar um tatu ou um veado por exemplo, pra sobreviver, pra se alimentar [...]" (entrevistado D), a caça ilegal prejudica a biodiversidade não só pela morte dos animais mas também por afugentar as demais espécies de seu habitat. A partir das entrevistas foi possível coletar alguns dados sobre espécies de mamíferos que os entrevistados possuem conhecimento que existem na microbacia e que são vistos ou que não são mais encontrados, diante disso estas informações foram compiladas na tabela que segue, a qual apresenta o nome popular, nome científico e nível de ocorrência das espécies na microbacia.

As imagens utilizadas para mapear as diferentes classes foram extraídas do Google Earth (DIGITAL GLOBE) com coordenadas UTM e sistema datum WGS84 e resolução espacial de quatro metros. $\mathrm{Na}$ microbacia do rio Mão Curta existem áreas de plantio realizado com o eucalipto (Eucalyptus spp) e/ou pinus americano (Pinus elliottii) estas também foram mapeadas e denominadas como reflorestamento, outras áreas de vegetação são os corredores os quais servem como conectores entre as 
manchas/fragmentos, os quais também estão representados no mapeamento.

A drenagem também foi destacada através do QGIS e o restante da imagem que não se encaixa em nenhuma destas classificações citadas acima não são áreas de habitat das espécies animais que pertencem a macrofauna por serem ocupados pelo homem e também por serem áreas de plantio de diversos cultivos, dessa forma degradadas e inviáveis para sobrevivência de mamíferos pela ausência de recursos alimentícios e hídricos de qualidade.

Tabela 1 - Ocorrência de espécies de mamíferos na microbacia do Rio Mão Curta baseada nas entrevistas realizadas com moradores do local.

\begin{tabular}{l|l|l}
\hline Nome comum & Nome científico & Ocorrência \\
\hline Tatu mulita & Dasypus septemcinctus & Ocasional $^{1}$ \\
\hline Veado mão curta & Mazama nana & Rara $^{2}$ \\
\hline Lebre & Lepus europaeus & Constante $^{3}$ \\
\hline Jaguatirica & Leopardus pardalis & Rara \\
\hline Onça-pintada & Panthera onca & Rara \\
\hline Paca & Agouti paca & Rara \\
\hline Cutia & Dasyprocta azarae & Rara \\
\hline Capivara & Hydrochaeris hydrochaeris & Constante \\
\hline Quati & Nasua nasua & Ocasional \\
\hline
\end{tabular}

\footnotetext{
${ }^{1}$ Espécies que dificilmente são vistas por moradores, mas que eventualmente são encontradas.

${ }^{2}$ Espécies que não são visualizadas atualmente na microbacia do rio Mão Curta, mas que em tempos remotos já foi vista pelos moradores.

${ }^{3}$ Espécies que podem ser vistas na área de estudo com maior frequência que ambas as classificações anteriores.
} 
(b) Mapeamento dos fragmentos e corredores ecológicos.

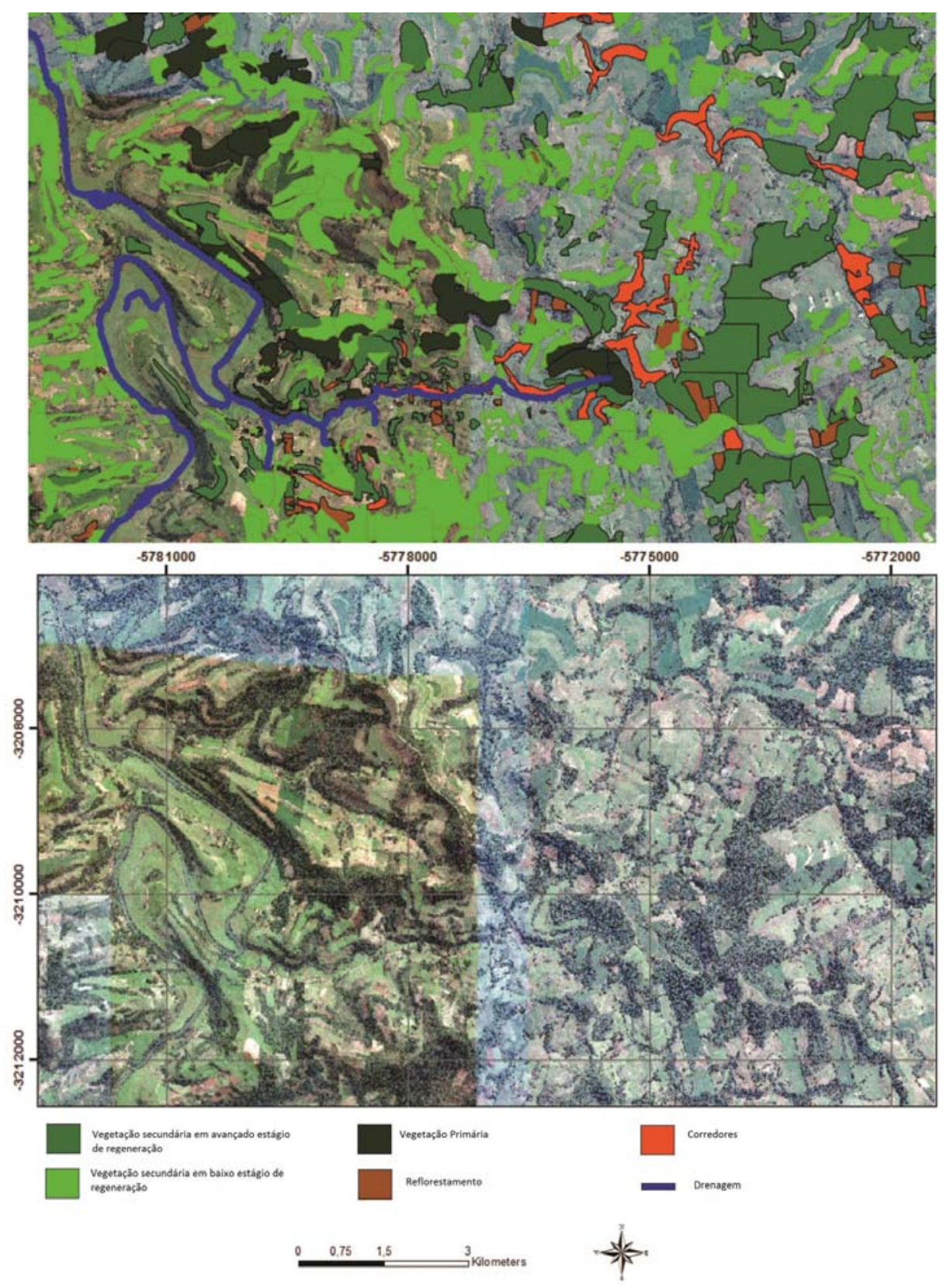

A partir do mapeamento (figura 03) foi possível identificar várias situações problemáticas referentes à estrutura da paisagem, como a fragmentação, que refletem diretamente na biodiversidade. Battisti (2004) em seus estudos aponta que a fragmentação de habitats na atualidade deve ser considerada a ameaça de ordem antrópica mais impactante a diversidade de espécies animais, segundo o autor a destruição e transformação de áreas naturais bem como o aumento do isolamento de fragmentos influenciam diretamente sobre as populações 
alterando sua dinâmica e posteriormente transformando as estruturas das comunidades, ecossistemas e processos ecológicos.

Ao realizar o mapeamento das diferentes classes vegetacionais observa-se que há cerca de oitenta fragmentos isolados de pequenas dimensões, outros pouco circulares, alguns possuem corredores de má qualidade, áreas de drenagem desprotegidas de mata ciliar, habitats retalhados por estradas, plantações ou outras interferências de ordem antrópica.

Metzger (1998), afirma em seus estudos que $\mathrm{o}$ isolamento de um fragmento tem influência negativa sobre a diversidade de espécies, pois reduz a capacidade de imigrações ou recolonização. Hess e Fischer (2001) especificam as funções que um corredor deve exercer: a primeira delas se trata de um elemento condutor, esta função é exercida quando o corredor serve como passagem para as espécies de um fragmento a outro, mas as mesmas não habitam o mesmo; o corredor pode servir como habitação para determinadas espécies onde as mesmas encontram condições favoráveis a sua sobrevivência e reprodução, este remanescente de mata pode ser visto como filtro quando ele tem a função de filtrar as espécies e/ou materiais que passam por ele, também é barreira, pois pode impedir que alguns organismos ou materiais passem por ele, 0 corredor serve como fonte quando organismos provêm do corredor e sumidouro, pois alguns organismos ou materiais adentram o corredor e são extintos.

O mapeamento gerado possibilitou analisar e, portanto, compreender que vários fragmentos de mata sofreram e sofrem interferência humana para a construção de estradas tanto para utilização de acesso as comunidades ou municípios vizinhos como para ter acesso às lavouras, as quais inicialmente eram feitas em áreas em que o terreno fosse propício a mesma e hoje se observa que a agricultura avança para áreas que outrora eram consideradas desfavoráveis devido à inclinação, mas que nos dias atuais com o auxílio de máquinas modernas possibilita a utilização destes terrenos.

Outro elemento importante observado e analisado na área de estudo se trata das formas de fragmento, as mesmas são importantes elementos de análise. Metzger (1998) ressalta que geralmente a área do fragmento é diretamente proporcional a sua biodiversidade, os efeitos do aumento da fragmentação, o número de fragmentos aumenta, diminui sua heterogeneidade e 
recursos também, aumentando o efeito borda, esses elementos influenciam diretamente no acréscimo de extinção das espécies, o isolamento entre os fragmentos causa diminuição da recolonização e todos os aspectos citados anteriormente causam a perda da biodiversidade.

Valeri e Senô (2004) apontam a teoria que trata da biogeografia de ilhas a qual "estuda a influência do tamanho do fragmento de habitat e do seu isolamento nas populações" (p.4), esta teoria afirma que pequenas ilhas contém um número menor de espécies em relação a ilhas maiores, possuem taxas de extinção elevadas, em contrapartida as ilhas que estão próximas a colonizadores abrigam maior quantidade de espécies devido às taxas de imigração que são otimizadas com a presença de corredores ecológicos já que este auxilia o movimento das mesmas entre as ilhas.

$\mathrm{Na}$ área de estudo observa-se que existem vários pontos em que há perda de conexão entre os fragmentos ou ainda há corredores com vegetação rarefeita, degradada e estreita, dessa forma os mesmos não exercem suas funções de forma eficaz. Na microbacia de estudo com - passar do tempo nota-se que os corredores vão sendo degradados devido à ação antrópica, pois as áreas para cultivo de soja, milho, trigo e pastagens, são ampliadas, com isso retira-se a vegetação nativa, destruindo habitats e também os corredores que fazem a conexão entre os fragmentos. Os corredores em muitos casos são estreitos e podem ser usados como armadilhas para predadores naturais, ou ainda para a caça antrópica. Assim como os corredores, os fragmentos possuem setores com a vegetação escassa, podendo estar relacionado ao desmatamento seletivo e clandestino de áreas que deveriam ser reserva natural.

O aumento da fragmentação traz diversas consequências uma delas é o aumento do efeito borda destes fragmentos, que reflete negativamente sobre os mamíferos. $\mathrm{O}$ efeito borda resulta do desmatamento entorno de fragmentos, e ainda corredores, e está relacionado com vegetações em estado de regeneração e de pequeno porte. As áreas de bordas dos fragmentos não oferecem abrigo seguro para os mamíferos, os quais tendem a ocupar preferencialmente as áreas centrais do fragmento, desta forma há pouca dispersão de sementes nas áreas de bordas. Também não há umidade suficiente para o desenvolvimento de algumas sementes, assim são áreas de escasso recurso natural. A identificação, realizada através do mapeamento $\mathrm{e}$ atividades de campo, possibilita identificar fragmentos de maiores dimensões menos 
degradados e com alta conectividade e disponibilidade de recursos naturais, estes representam áreas de atenção especial para o planejamento de ações que visem sua preservação ambiental.

Os fragmentos identificados como os mais degradados e que ainda possuem recursos hídricos e conectividade deve ser considerados como importantes para 0 planejamento de ações de recuperação ambiental, pois são áreas de maior potencial restaurativo da fauna e flora do bioma local. Os fragmentos menores e pouco circulares, isolados e sem recursos naturais são áreas que podem representar ausência de espécies da fauna, como muitas aves e mamíferos do bioma natural. Com a diminuição/ausência destas espécies, que se alimentavam e se locomoviam, dispersando sementes de espécies frutíferas, há a diminuição progressiva dos recursos naturais. Dessa forma, a presença de corredores se torna primordial já que estes possibilitam a locomoção das espécies bem como o intercambio genético das mesmas, ainda auxilia na proteção do solo e dos recursos hídricos (LANG, 2009).

Muitos fragmentos por seu grau de isolamento e escasso recurso natural não possibilitam mais o desenvolvimento de muitas espécies de animais, sendo considerados como "florestas vazias". Estas áreas devem ser de especial interesse para o desenvolvimento de estudos, ações e o contínuo monitoramento visando à restauração das condições ambientais que propiciem o desenvolvimento progressivo das espécies do bioma natural.

Pode-se afirmar que pelo menos oitenta fragmentos da área de estudo sofrem com o efeito borda devido ao seu tamanho relativamente pequeno e pouco circular, este efeito influencia negativamente sobre os fragmentos e sua biodiversidade, uma vez que altera a temperatura e umidade na direção bordainterior. A partir dos trabalhos de campo e mapeamentos tornou-se possível identificar que o número de fragmentos menores, menos circulares e desconectados sobressaem-se sobre os demais que possuem recursos hídricos, conectividade e alimentos.

\section{CONSIDERAÇÕES FINAIS}

Na microbacia do rio Mão Curta observa-se que não são praticadas de forma significativa técnicas que visem a conservação de florestas e drenagem, principalmente, prática que minimiza impactos sobre a fauna quando comparado ao uso não manejado destes recursos, já que desta forma a cobertura vegetal é mantida, contribuindo para o equilíbrio 
ambiental e conservação do ciclo hidrológico.

Alguns problemas que podem estar conectados a fatores prejudiciais aos diferentes hábitat ali existentes são o cultivo agrícola sem manejo adequado, o desmatamento, e outros, os quais podem ser alguns dos aspectos da diminuição de espécies relacionados à macrofauna.

Estes aspectos podem ter sua interferência na mudança de quantidade de espécies animais, pois pode causar danos ambientais através da diminuição de recursos naturais como seus alimentos, nichos e também da poluição dos cursos de água, entre outros aspectos. Realizar estudos relacionando modificações no ambiente e a possível diminuição de algumas espécies da fauna nativa deste local tem elevada importância, pois conhecendo-se o problema e as causas é possível realizar ações de conservação para a restauração dos aspectos relacionados com a manutenção das funções ecológicas essenciais no contexto inserido. Portanto, os resultados desta pesquisa tem relevância tanto para a produção de conhecimento como para servir de subsídios na resolução do problema em questão através do planejamento de ações efetivas de conservação do local.

Entretanto, para que exista a conscientização dos moradores do local sobre a conservação da área é importante que se identifique os fatores degradantes da biodiversidade e alternativas que sejam sustentáveis e eficazes na recuperação das áreas degradadas. Há diversos tipos de fragmentos, alguns com maior potencial de restauração e outros menos, ao se pensar - planejamento de ações para a recuperação ambiental as áreas que ainda possuem recursos hídricos e conectividades devem ser consideradas, haja vistas que estes possuem poder restaurativo da fauna e flora de forma acelerada em relação aos isolados e sem ligação aos recursos hídricos.

A partir de trabalhos de campo, foi possível analisar que há vestígios da macrofauna em fragmentos com menor índice de degradação, que apresentem corredores, fonte de alimentos, recursos hídricos, enquanto os que não apresentem tais características são afetados pela pressão que o homem exerce através de seus cultivos e uso de agrotóxicos com maior intensidade não tendo os registros de mamíferos. Foram encontradas em maior quantidade tocas que são características de tatu, neste caso o tatu mulita (Dasypus septemcinctus). No total foram duas tocas encontradas num total de cinco pontos visitados, uma trilha e pegadas de capivara. Em dois locais que foi realizado trabalhos de campo não foram 
encontrados vestígios. Ressalta-se que as técnicas aplicadas em campo somadas às consultas bibliográficas realizadas deram suporte para as análises sobre as mudanças na distribuição biogeográfica e relações com as alterações no habitat de mamíferos que vem acontecendo no local.

As entrevistas com moradores da microbacia foram de extrema importância para obtenção de informações acerca de mudanças na paisagem e na distribuição zoogeográfica de espécies da macrofauna, os entrevistados adquiriram conhecimento a partir de sua vivência no local, dessa forma contribuíram com seu conhecimento empírico acerca dos fatos em uma entrevista dialogada entre os mesmos.

Os elementos como desmatamento, ocupação agrícola, diminuição de acesso à drenagem, prática da caça e o uso de agrotóxicos influenciam na distribuição biogeográfica de espécies que pertencem a macrofauna na área de estudo, haja vista que a combinação destes

\section{REFERÊNCIAS}

\section{ATLAS SOCIOECONÔMICO DO ESTADO DO} RIO GRANDE DO SUL. Disponível em: http://www.scp.rs.gov.br/atlas/ acesso em 05/12/2013.

BATTISTI, Corrado. Frammentazione Ambientale Connettivita Reti Ecologiche. Um Contributo teórico e metodológico com Particolare Referimento ala fauna selvática. Roma. 2004. fatores pressiona os remanescentes florestais e seus recursos hídricos e alimentícios os quais são responsáveis pela manutenção da biodiversidade.

Os resultados contribuem para 0 planejamento de ações de conservação ambiental na área de estudo, já que este buscou identificar elementos degradantes para a biodiversidade e as consequências que estas geram e como impactam as espécies da macrofauna, uma vez que a eficácia da conservação depende desta identificação e os resultados que foram obtidos apontam para a necessidade de ações urgentes de recuperação da paisagem visando à manutenção dos recursos indispensáveis a biodiversidade. Estas ações se tratam de um grande desafio, mas devem envolver e conscientizar a comunidade local e que esta tome conhecimento da importância de um desenvolvimento sustentável tanto para o homem como para as demais espécies.

BRASIL. Conselho Nacional do Meio Ambiente -CONAMA. Resolução $n^{\circ} 417$ de 23 de novembro de 2009. Disponível em: http://licenciamento.cetesb.sp.gov.br/legis lacao/federal/resolucoes/2009_Res_CONA MA_417.pdf Acesso em: 14/11/2014.

COLLINGE, S. K. Ecological consequences of habitat fragmentation: implications for landscape architecture and planning. Landscape and Urban Planning. v.36, n. 1. 1996. 
EMBRAPA. Sustentabilidade Agrícola e Biodiversidade Faunística. Disponível em: http://www.biodiversidade.cnpm.embrapa .br/ambiental/mamiferos/tatu_mulita.html Acesso em: 15/11/14.

FORMAN, R. T. T. Land mosaics: the ecology of landscape end regions. Cambridge: Cambridge University Press. 1995. 632p.

HESS, G. R.; FISCHER, R. A. Communicating Clearly About Conservation. Landscape Urban Planning. V. 55, P. $195-208,2001$. Disponível em:

http://carmelacanzonieri.com/library/6123 /Hess-

CommunicatingClearlyConsvCorridors.pdf Acesso em: 05/10/2014.

HIRT, C. Impactos dos Monocultivos arbóreos na paisagem e nas Atividades Relacionadas ao Turismo em São Francisco de Paula/RS. 2009. (Dissertação) Mestrado em Geografia. Universidade Federal do Rio Grande do Sul. 2009.

INSTITUTO BRASILEIRO DE GEOGRAFIA E ESTATÍSTICA. Rio Grande do Sul, Sananduva, infográficos: dados gerais do município. Disponível em:

http://ibge.gov.br/cidadesat/painel/popula cao. php?lang $=\&$ codmun $=431660 \&$ search $=r$ io-grande-do-sul|sananduva|infograficos:evolucao-populacional-e-piramide-etaria. Acesso em 03/01/2015.

\section{INSTITUTO CHICO MENDES DE} CONSERVACAO DA BIODIVERSIDADE.

Combate à caça e a pesca de animais. Disponível em:

http://www.icmbio.gov.br/portal/comunic acao/noticias/4-destaques/3747-icmbiocombate-caca-e-trafico-de-animais.html acesso em 24/12/2013.

INSTITUTO CHICO MENDES DE CONSERVACAO DA BIODIVERSIDADE. Lista de Espécies Ameaçadas. Disponível em: http://www.icmbio.gov.br/portal/biodivers idade/fauna-brasileira/lista-deespecies.html?limitstart $=0$. Acesso em: 05/07/2014.

LAGO, F. P.L. S CHAVES, H. M. L.; GALVÃO, W. S. Avaliação da estrutura da paisagem para o Parque Nacional Grande Sertão Veredas, através de análise de imagens de Sensoriamento Remoto. In: X Anais SBSR, 2001. Foz do Iguaçu. INPE. p. 1633-1640.

LANG, S.; BLASCHKE, T. Análise da Paisagem com SIG. São Paulo. Oficina de Textos. 2009.

METZGER, J. P. Estrutura da Paisagem e Fragmentação: Análise Bibliográfica. Anual da Academia Brasileira de Ciências, v. 71, n. 3-I, p. 445-463, 1998.

MMA - Ministério do Meio Ambiente. Avaliação e identificação de áreas e ações prioritárias para a conservação, utilização sustentável e repartição dos benefícios da biodiversidade nos biomas brasileiros. Brasília: MMA/SBF, 2002.

MORATO, E. F.; CAMPOS, L. A. O. Efeitos da fragmentação florestal sobre vespas e abelhas solitárias em uma área da Amazônia Central. Revista Brasileira de Zoologia. v.17, n. 2, p. 429-444, 2000.

NETO, O. MOREIRA, M. SUCENA, L. F. Grupos Focais e Pesquisa Social Qualitativa: o debate orientado como técnica de investigação. 2002. Disponível em: http://empreendetche.unisc.br/portal/upl oad/com_arquivo/grupos_focais_e_pesqui sa_social_qualitativa_o_debate_orientado _como_tecnica_de_investigacao.pdf acesso em: 30/04/2014.

RICKLEFS, R. E. A economia da natureza. 3 ed. Rio de Janeiro: Editora Guanabara Koogan, 1996. 470p. 
ROCHA, Y. T. Técnicas em Estudos Biogeográficos. Revista Raega. Curitiba. V. 23 p. 398-427. 2011.

ROSSATO, M. S. Os Climas do Rio Grande do Sul: Variabilidade, Tendências e Tipologias. 2011. (Tese) Doutorado em Geografia. Universidade Federal do Rio Grande do Sul. 2011.

SCD - Secretariado da Convenção sobre Diversidade Biológica, Panorama da Biodiversidade Global 3, Brasília, Ministério do Meio Ambiente, Secretaria de Biodiversidade e Florestas (MMA), 2010.

SILVA, Flavio. Mamíferos Silvestres - Rio Grande do Sul. $2^{\text {a }}$ ed. Porto Alegre, Fundação Zoobotânica do RS. 1994, p. 177.

SONEGO R. BACKES A. Souza A. Descrição da estrutura de uma Floresta Ombrófila Mista, RS, Brasil, utilizando estimadores não-paramétricos de riqueza e rarefação de amostras. Disponível em: http://www.scielo.br/pdf/abb/v21n4/a19v 21n4.pdf acesso em: 30/04/2014.

STEVENS, S. M.; HUSBAND, T. P. The influence of edge on small mammals: evidence from Brazilian Atlantic forest fragments. Conservação Biológica, v. 85, n. 1-2, p. 1-8,Julho-Agosto. 1998.

STRECK, E. V.; KÄMPF, N.; DALMOLIN, R. S.; KLAMT, E.; NASCIMENTO, P. C.; SCHNEIDER, P.; GIASSON, E.; PINTO, L. F. S.Solos do Rio Grande do Sul. 2ㅇ ed. Porto Alegre: Emater/RS-Ascar, 2008. 222 p.

VALERI, S. V.; SENÔ, M. A. A. F. A importância dos corredores ecológicos para a fauna e a sustentabilidade de remanescentes florestais. In: 80 Congresso Internacional de Direito Ambiental, 2004, São Paulo. Fauna, políticas públicas e instrumentos legais. São Paulo: Impresaoficial, 2004. v. 1. p. 699-709.
VIADANA, A. G.. Biogeografia: Natureza Propósitos e Tendências. In: Antônio Carlos Vitte; Antônio José Teixeira. (Org.). Reflexões sobre a Geografia Física no Brasil. Rio de Janeiro: Bertrand, 2004. 